\title{
Research on the Construction of the Software Specialty Oriented Ecological Network Homework Platform
}

\author{
Kechao Wang ${ }^{1,2, a^{*}}$, Tiantian Wang ${ }^{2, b}$, Xiangmin $\operatorname{Ren}^{1, c}$ and Na Man ${ }^{1, d}$ \\ ${ }^{1}$ School of information Engineering, Harbin University, Harbin, China \\ ${ }^{2} S$ chool of Computer Science and technology, Harbin Institute of Technology, Harbin, China \\ aerickcwang@126.com, bsweetwtt@126.com, min0070@sina.com, ${ }^{\mathrm{d} m n}$ [0451@163.com
}

Keywords: Ecological teaching environment; Network homework platform; Automatic scoring; Plagiarism detection; Duplicate detection

\begin{abstract}
In view of the problems that the homework of students majoring in software can not be submitted anytime and anywhere, students have no smooth communication with their teachers and other students, the phenomenon of homework plagiarism is serious, and the work efficiency is low, which is caused by the teacher's manual check for plagiarism and teacher's manual scoring on program design homework, a software specialty oriented ecological network homework processing model is put forward and an ecological network homework platform is constructed. It has preliminarily solved the key problems of the current student's homework management, improved the work efficiency of teachers and aroused the students' interest in self-study.
\end{abstract}

\section{Introduction}

Currently, there are two types of homework of students majoring in software: one is the type of document, such as doc, pdf and so on, and the other is the type of program. After-class assignments, experiment, classwork, course design, stage test, forum, and online creation are all known as the homework.

At present, the outstanding problems in the management of students' homework are that the homework is submitted in a traditional exercise book way, students can't make full use of the Internet to submit their homework anytime and anywhere, students can't communicate with teachers and classmates anytime and anywhere in the process of doing homework, the work efficiency of teachers is low, which is caused by the serious homework plagiarism and the teacher's manual check for plagiarism, the program type homework needs manual judgement by the teacher, the judgement of the grammatical and semantic errors in the program will often be missed, and the correctness of the program can not be fully grasped.

In view of the above problems, based on the teaching idea of social constructivism, we build a software specialty oriented ecological network homework platform[1-8], provide the teacher oriented homework management platform, including the release of homework, automatic grading of program type homework, the intelligent plagiarism detection of homework, homework evaluation feedback and others, and also provide the student oriented homework submission platform, including homework viewing, online submission, autonomous learning, score and feedback viewing, mutual answering questions and discussion, and other functions.

\section{Ecological Network Homework Platform}

The so-called ecological network teaching[1-2] refers to the teachers' teaching and students' learning based on the network platform under the guidance of advanced educational thought, teaching theory and learning theory, and the process of teaching and learning should have the basic characteristics of interactivity, cooperation, autonomy, openness, personality and sharing.

The ecological network homework platform[3-4] is built on the basis of the ecological network teaching environment, including the teacher oriented open ecological network homework management platform, and the students' autonomous learning oriented homework submission 
platform, as shown in Fig. 1.

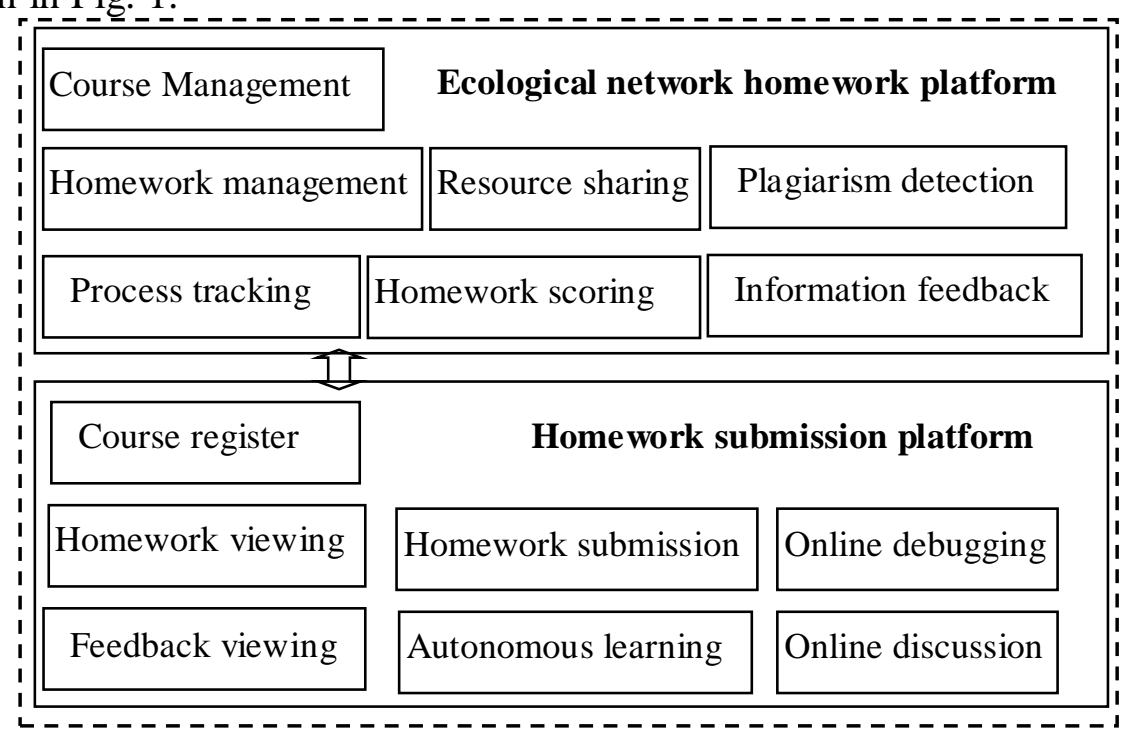

Figure 1. Functional schematic diagram of ecological network homework platform

The Teachers Oriented Open Ecological Homework Management Platform. The first one is the course management. A teacher oriented open ecological management platform supports unlimited course catalogues and content creation. The course can be set as the activated or hidden state. The flexible permission, class level, key, and the option that allows students to quit the course are set up. Flexible curriculum activities, such as forums, logs and tests, can also be set up. The teacher can also pack and backup the course.

The second one is the homework release. When a teacher releases homework, he can set assignments, scores, submission forms, deadline, whether he can allow students to submit late, and whether the students can submit again after submission. If it is the program type homework, he can limit the programming language that must be used or the knowledge points that must be used, etc.

The third one is the homework scoring. If the student's submission is a document form, the teacher's manual scoring is required. If it is a program type homework, it can be automatically scored by the platform[5-6]. The teacher can also modify the results of the automatic evaluation of the platform, and evaluate and feed back the students' homework.

The fourth one is the resource sharing. Teachers can not only release the teaching courseware, teaching materials and teaching tools for students to learn independently, support the display of common electronic documents, including word, ppt, pdf, flash, video and audio, which can be stored locally or remotely, but also release all kinds of teaching notices. The student's mailbox will automatically and immediately receive a notice.

The fifth one is the information feedback. Teachers can manually evaluate and score the homework of the whole class on one page. Scoring feedback will be displayed on each student's homework page and there will be e-mail to inform the students. The teacher can also get feedback from students in time to better understand the students through the functions of questionnaire and voting provided by the platform.

The sixth one is the plagiarism detection. The plagiarism detection function is provided for program type homework[7] and document type homework[8] (supporting doc, pdf, and txt formats).

The seventh one is the full tracking and analysis of teaching process. The platform uniformly manages the achievement of all kinds of students' homework (including stage testing, forum, online creation, etc.). The teacher can set the weight of each activity, and support the bonus points, rank, etc., which is a good tool for the accumulative examination.

In the process of using this platform to teach, the system records the teaching process, events, students' questions, and homework scores in detail, and makes corresponding statistical analysis of the records, forming a large number of teaching records. The system provides many management functions to these files, so that teachers can analyze and master the teaching situation from various 
aspects.

The Students' Autonomous Learning Oriented Network Submission Platform. The first one is to join the course. After the teacher has finished a course of registration, the student can apply for joining the course. After authentication, the student can succeed in joining the course.

The second one is the autonomous learning. After joining a course, students can choose the subject set by the leading teacher of this course, read the teachers' teaching plans, watch the multimedia courseware, and arrange the autonomous learning according to the curriculum designed by the teacher.

The third one is the homework viewing. After the teacher has released the homework, the students can see the contents and requirements of this assignment through the teaching platform or registered mailbox.

The fourth one is the homework submission. After the completion of the homework, the student may submit it online at any time or any place before the deadline of submission. For the homework that has been submitted, if the repeated submission is allowed and set by the teacher, students can modify and submit it repeatedly before the deadline. The platform will be subject to the final submission.

The fifth one is the mutual aid online questioning and discussion. Students can ask teachers and other students questions through the course discussion area or chat room, and these questions can be answered and communicated between students or between teachers and students.

The sixth one is the online debugging. For the homework that has been submitted, students are allowed to modify and submit it many times before the deadline. For program type homework, after students submit the homework, the automatic scoring system provided by the teaching platform will automatically score, and give grammatical errors or warning notices. Students can modify and debug their own homework programs online.

The seventh one is the feedback viewing. Once the students' homework is scored(no matter whether it's the teacher's manual score or the automatic scoring of teaching platform), the students can see the score and the evaluation of the homework given by the teacher through a platform or a registered mailbox.

\section{Ecological Network Homework Processing Model}

The ecological network homework processing model has six links: homework release, view, scoring, submission, plagiarism detection and feedback viewing, as shown in Fig.2.

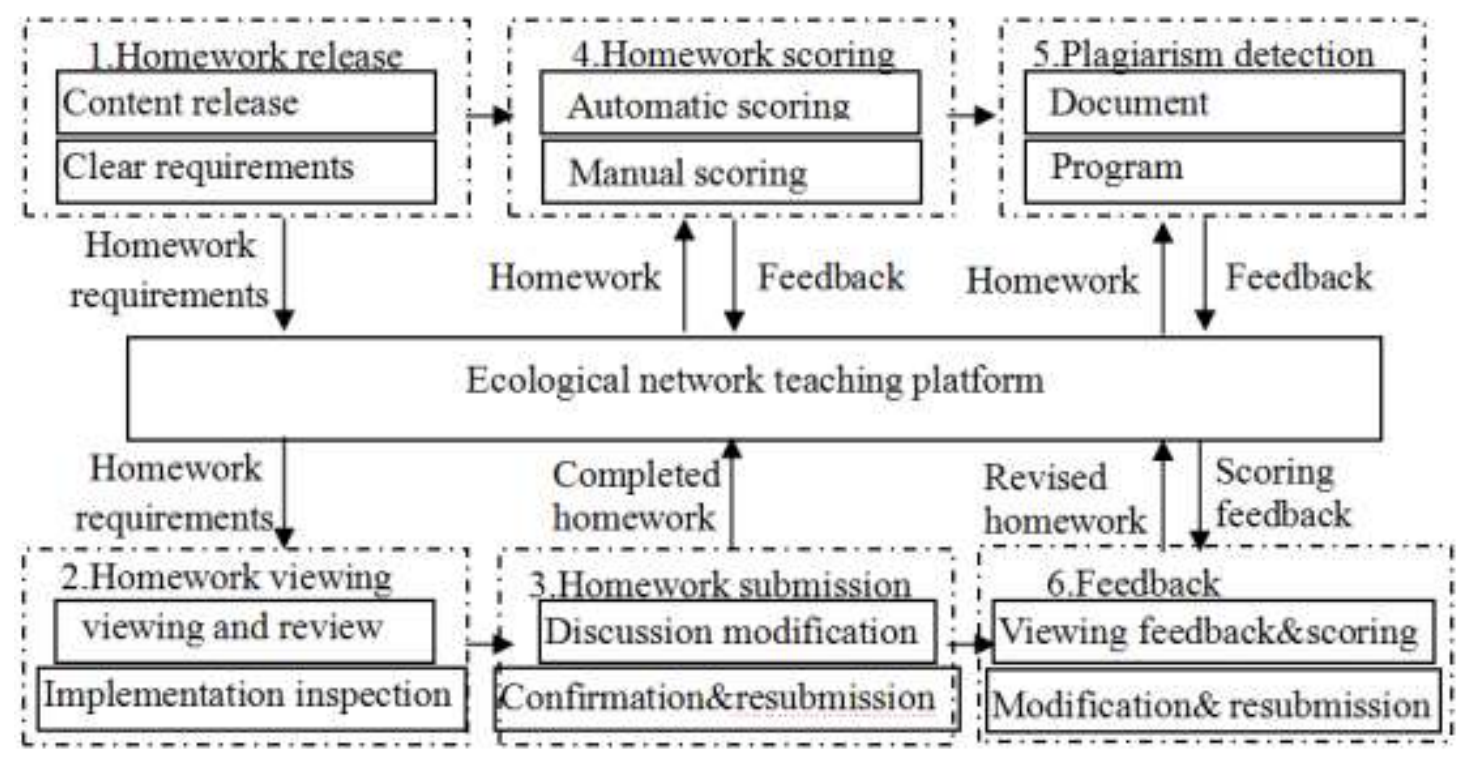

Figure 2. Ecological network homework processing model 
The first step is the homework release. The teacher releases homework based on platform, and clarifies the contents and requirements of the homework, such as the setting of the knowledge points and the deadline that must be used for this homework. The document type homework should be specified as doc, pdf, or other formats. The program design type homework must specify the programming language, etc.

The second step is to view and complete the homework. After seeing the homework released by the teacher on the platform, the students should carefully view the requirements of the homework, and comprehensively use the knowledge to complete the homework. For example, when they meet difficulties or they confuse, they can use the forum provided by the platform to discuss these questions with other students and teachers in order to solve these problems.

The third step is the homework submission. After the students complete the homework, they can submit their homework to the homework platform at any time before the deadline.

The fourth step is the homework scoring. After the submission of the homework, the homework will be scored. If the homework belongs to the document type homework, it requires the manual evaluation by teachers. When the teachers give the score, they can evaluate students' homework and make the feedback. As for the homework about program design, through the automatic scoring function of the program design question of the platform, the source code submitted by the student is automatically scored by the platform. The teacher can also modify the results evaluated by the platform, and evaluate the students' homework and make the feedback. After the completion of the evaluation, the platform will automatically send the results and feedback to the students and send them to the student's mailbox.

The fifth step is the plagiarism detection. After the deadline, the teacher can check the plagiarism list of the homework through the plagiarism detection function provided by the platform. If the teacher confirms the plagiarism, the system will send a plagiarism confirmation message.

The last step is the feedback viewing. Students can see the feedback information such as achievement evaluation, feedback or plagiarism confirmation through the platform.

\section{Conclusion}

In view of the types and characteristics of the homework of students majoring in application software and the existing problems to be solved urgently, this paper builds a software specialty oriented ecological network homework platform, provides the teacher oriented homework management platform, including the release of homework, automatic grading of program type homework, the plagiarism detection of homework, homework evaluation feedback and others, and also provides the student oriented homework submission platform, including homework viewing, online submission, autonomous learning, score and feedback viewing, mutual answering questions and discussion, and other functions.

Through the functions provided by the platform, such as online release and submission of homework, and curriculum forums, the traditional homework management problems which are limited by time and space have been solved, and the change of traditional homework release and submission is realized. Students can submit their homework anytime and anywhere, communicate with their classmates and teachers anytime and anywhere, and the function of a teacher's one button to backup and archive students' homework is realized.

The document homework plagiarism detection and program homework code duplication detection function provided by the platform bring pressure to students' plagiarism, and objectively urge the students to learn independently and complete their homework autonomously. At the same time, the teacher does not have to manually check the plagiarism of the homework, which improves the work efficiency of the teacher.

Through the automatic scoring function of program homework provided by the platform, the teacher can extricate himself from the manual detail detection of grammatical and semantic errors, and guide the efficiency and programming style of the students' program homework algorithm from the macro level. At the same time, after the students submit the program homework online, the platform will score automatically and feed back the score results to the students. When students see 
the feedback, they can modify the programs, debug them repeatedly and resubmit them until they are completely correct, which stimulates students' interest in self-study, and improve students' ability to analyze problems and debug programs.

After several years of teaching practice, we can see that the construction of the ecological network homework platform has strong practicability. It is widely welcomed by teachers and students, and it improves the working efficiency and working effect of teachers, and better understands the real learning situation of students, and meanwhile, it also inspires the students' interest in learning. The ability of independent learning and homework completion is significantly enhanced, the frequency of plagiarism phenomenon is significantly reduced, the communication between teachers and students increases significantly, and the students' ability to analyze and solve practical problems is obviously improved by the comprehensive application of the knowledge they have learned. Of course, in the construction of homework platform, we need to continue to optimize the algorithm, improve the function, and do further exploration.

\section{Acknowledgements}

This research is supported by Heilongjiang Education Science Project.

\section{References}

[1] Yu Jiayun. Theory and practice of ecology teaching[D]. Nanjing: Thesis of Nanjing Normal University, 2006.

[2] Li Aixia. Design and application of flipped classroom teaching model based on Moodle platform[D]. Chongqing: Chongqing Normal Univerisyt. 2017.

[3] http://cms.hit.edu.cn [Z].

[4] Xie Shumin. Research on the design and application of Web-based collaborative learning based on Moodle [D]. Wuhan: Thesis of Central China Normal University. 2015.

[5] Ma Peijun, etc. Automatic grading of student programs based on program understanding[J]. Journal of Computer research and Development, 2009,46(7).

[6] Wang Tiantian. Ability-training-oriented automated assessment in introductory programming course [J], Computers and Education, January 2011,v 56, n 1.

[7] Zhu Bo, etc. Research on similarity measure for AST-based program codes[J]. Journal of Jinlin University, 2015,01(33).

[8] Tai Xinguo, etc. Design and implementation of plagiarism detection system[J]. Journal of Nanjing Audit University, 2008,5(3). 